\title{
AOR
}

Selected Papers of \#AoIR2020:

The $21^{\text {st }}$ Annual Conference of the

Association of Internet Researchers

Virtual Event / 27-31 October 2020

\section{DISABILITY AND MENTAL HEALTH AS A PROFESSIONAL LIVE STREAMER}

Mark R Johnson PhD

Department of Media and Communications, University of Sydney

\section{Introduction: Live Streaming}

Twitch.tv is the dominant market leader in the broadcast of live user-created video content - primarily, but not exclusively, the play of video games - over the internet. In 2016 Twitch broadcasted over half a million years of video content, produced by over two million regular 'streamers', to an audience well in excess of 100 million people (Twitch, 2017a). Pires and Simon (2015, p. 225) define live streaming as a platform or practice through which 'anyone can become a TV provider'. Such terminology gives some hint as to the potentially revolutionary nature of the platform, taking an activity such as television broadcast out of the hands of economically powerful actors and handing it to ordinary individuals. This is similar to the analysis put forward by Cunningham and Craig (2016, p. 5412), who call Twitch 'social media entertainment', representing the blurring of traditional forms of broadcast media with the rapid back-and-forth of conversation between streamers and viewers. At one end, there are streamers broadcasting for the first time from their bedrooms, viewed by perhaps a handful of individuals. At the other are professional streamers with top-of-the-range broadcasting equipment, watched by tens of thousands at any one time and millions over longer periods, and who can comfortably bring in six-figure incomes. A core element of successful streams is the ability for viewers to talk directly to streamers through a facility known as 'Twitch Chat' or simply 'Chat', which allows streamers to immediately reply to viewers. Such a shrinking of the distance between media producer and media consumer, and the centrality of this responsiveness to the success of the phenomenon, highlights the profound newness and wider importance of live streaming in a rapidly changing media ecosystem. Equally, by providing opportunities in the digital economy to thousands at a rate expanding every day, it is also of great interest for scholars of digital labour, digital work, and the digital economy.

\section{Disability, Technology, and Streaming}

Suggested Citation (APA): Johnson, M. (2020, October 28-31). Disability and Mental Health as A Professional Live Streamer. Paper presented at AoIR 2020: The 21 ${ }^{\text {th }}$ Annual Conference of the Association of Internet Researchers. Virtual Event: AolR. Retrieved from http://spir.aoir.org. 
Despite a growing body of scholarly literature addressing the phenomenon, questions of inclusion and exclusion on the platform have been relatively scarce. Scholars have considered the place and presentation of gender, sex and sexuality on the platform (Witkowski, 2011) and also the dynamics of race on Twitch (Gray, 2017), all of which have shed significant light on inequalities and privilege in live streaming. By contrast, however, questions of disability, mental health, and physical illness in live streamers have not yet been explored. In turn, scholarship on people with these conditions in the digital economy and digital inclusion has not yet addressed this major new form of online behaviour. Contemporary scholarship therefore shows that disability entails a complex web of 'social, political and material disadvantage' (Lupton \& Seymour, 2000, p. 167) rather than simply a question of 'health' or 'ability', and that technological solutions - however well-intentioned - are far more complex than offering a simple objective or positivistic 'answer'. Given these elements, Twitch is an interesting site for exploring the intersection of disability and technology: the platform is very clear about its desires for inclusion (Twitch, 2017b), yet predicated on a deeply new and underexamined media technology which is complex, demanding, and technically and socially sophisticated. As such, in this paper I offer the first sustained scholarly exploration of the economic and inclusion opportunities for people with disabilities, physical health issues, or mental health issues afforded by 'live streaming' on the Twitch platform (Johnson, 2018); from this point on I use the broader term 'chronic conditions' to refer to all of these. In doing so I will explore the extent to which digital inclusion can lead to social inclusion for people with disabilities; how the digital economy and digital entrepreneurship through live streaming present opportunities for empowerment; and the potential roadblocks and hurdles along such a path.

\section{Research Project}

To do so I begin with a review of existing literature in three areas: the 'digital economy'; the relationship between (dis)abilities, health and technology; and Twitch and the live streaming phenomenon itself. I then move to a discussion of methodology, which consists primarily of drawing upon a corpus of over 100 interviews with successful live streamers on Twitch, alongside ethnographic data from both online and offline locations. I then proceed to my central analysis, which I divide into two sections. I first explore the positives of the streaming experience for those with chronic conditions, primarily community and inclusion, especially noting the distinctive kinds of streams that these broadcasters have been able to create on the platform. I then consider the negatives, especially in terms of the unique challenges that individuals with chronic conditions might face in the process of live streaming, created through intersections between the social expectations and material form of Twitch, and 'real world' health. The paper then uses these findings to assess the economic and entrepreneurial importance of these two aspects, and conclude by weighing up the value of live streaming to individuals with chronic conditions.

By developing these discussions from interview and ethnographic data, I analyse how disability and health intersect with the major new media practice of live streaming and the opportunities in the digital economy that it affords. Through these three enquiries I argue that Twitch offers a way to provide digital opportunities for people with chronic 
conditions, but one where complex differentiations and hierarchies nevertheless continue to manifest. All streamers with chronic conditions asked to assess the 'balance' fell firmly on the side of the positive effects over the negative effects, in line with previous findings about streamers' rationalisations of the working pressure of the career (Johnson \& Woodcock, 2017). Although live streaming is the most contemporary of these, its immense growth and the numbers for viewers and producers demonstrates it cannot be overlooked. Live-streaming looks set to be the 'next big thing' in digital media, and it thus the opportunities and inequalities it presents demand attention.

\section{References}

Cunningham, S., \& Craig, D. (2016). Online entertainment: A new wave of media globalization? International Journal of Communication, 10, 5409-5425.

Gray, K. L. (2017). 'They're just too urban': Black gamers streaming on Twitch. In J. Daniels, K. Gregory, \& T. McMillan Cottom (Eds.), Digital sociologies (pp. 355-367). Bristol: Policy Press.

Johnson, M. R. (2018). Inclusion and exclusion in the digital economy: Disability and mental health as a live streamer on Twitch. tv. Information, Communication \& Society, 22(4), 506-520.

Johnson, M. R., \& Woodcock, J. (2017). 'It's like the gold rush': the lives and careers of professional video game streamers on Twitch. tv. Information, Communication \& Society, 22(3), 336-351.

Lupton, D., \& Seymour, W. (2000). Technology, selfhood and physical disability. Social Science \& Medicine, 50(12), 1851-1862.

Pires, K., \& Simon, G. (2015). YouTube live and Twitch: A tour of user-generated live streaming systems. 6th ACM multimedia systems conference, Portland, Oregon, 225230

Twitch. (2017a). Audience. Twitch. Retrieved from http://twitchadvertising.tv/audience/

Twitch. (2017b). Twitch cares: Mental health support \& information. Twitch. Retrieved from https://help. twitch.tv/customer/portal/articles/2904486-twitch-cares-mental-healthsupport-information

Witkowski, E. (2011). Following Ms_Fabulous: Women, live-streaming, and do-ityourself visibility in e-sports. Proceedings of the Annual meeting for the Digital Games Research Association, Hilversum, Netherlands, 14-17. 